\title{
Divergência genética de populações de Piper hispidinervum C. DC. com base em caracteres morfoagronômicos ${ }^{1}$
}

\author{
Jacson Rondinelli da Silva Negreiros ${ }^{2}$, Daniela Popim Miqueloni ${ }^{2}$
}

\begin{abstract}
Genetic divergence of Piper hispidinervum C. DC. populations concerning morphoagronomic traits

In order to generate information for the Piper hispidinervum breeding program, in the Acre State, Brazil, the genetic divergence among fifteen populations collected in different regions of the State was evaluated. The following morphoagronomic traits were assessed: leaf length and width, petiole length and diameter, canopy volume, essential oil yield and safrole content (major component of this essential oil). Cluster analyses, using the Tocher's optimization and single linkage methods, besides the canonical variables analysis, were applied. Significant differences were observed in all traits. The Tocher's grouping method allowed to identify three divergent groups. The first three canonical variables accounted for $76 \%$ of the original data variance, forming four groups that corroborated most the results of the previous analysis. The two most important variables for distinguishing the groups were the safrole content and the essential oil yield, which were considered basic for the selection of superior genotypes. The similarity or divergence groups allowed to identify populations with interesting characteristics for breeding programs involving this species.
\end{abstract}

KEY-WORDS: Long pepper; safrole; essential oil; genetic variability.

\section{INTRODUÇÃO}

A espécie Piper hispidinervum C. DC. é popularmente conhecida como pimenta longa. Ganhou notoriedade a partir da década de 1970, quando pesquisadores do Instituo Nacional de Pesquisas da Amazônia (INPA) e do Museu Emílio Goeldi realizaram inventário de plantas aromáticas da Amazônia e destacaram-na como espécie rica em óleos essenciais, com rendimento variando entre $3,0 \%$ e $4,8 \%$ e teores de safrol de $89 \%$ a $98 \%$, sendo, este, o componente majoritário nestes óleos essenciais (Gottlieb et al. 1981, Maia et al. 1987, Andrade et al. 2009).

\section{RESUMO}

Com o intuito de gerar informações para o programa de melhoramento de pimenta longa (Piper hispidinervum), no Estado do Acre, avaliou-se a divergência genética entre quinze populações coletadas em diferentes regiões do Estado. Foram avaliados os seguintes caracteres morfoagronômicos: largura e comprimento da folha, comprimento e diâmetro do pecíolo, volume de copa, rendimento de óleo essencial e teor de safrol (componente majoritário deste óleo essencial). Foram aplicadas análises de agrupamento, pelos métodos de otimização de Tocher e do vizinho mais próximo, além da análise de variáveis canônicas. Houve diferenças significativas em todas as características estudadas. O agrupamento pelo método de Tocher permitiu identificar três grupos de divergência. As três primeiras variáveis canônicas explicaram $76 \%$ da variância original dos dados, resultando em quatro grupos, que corroboraram, em grande parte, os resultados da análise anterior. As duas variáveis de maior importância, na discriminação dos grupos, foram o teor de safrol e o rendimento de óleo essencial, que se mostraram básicos, para a seleção de genótipos superiores. Os grupos de similaridade ou de divergência permitiram identificar populações com características de interesse para programas de melhoramento da espécie.

PALAVRAS-CHAVE: Pimenta longa; safrol; óleo essencial; variabilidade genética.

O safrol é um fenilpropanoide que, por meio de transformações químicas, gera outros compostos de grande interesse, como a heliotropina e o butóxido de piperonila. A primeira é matéria-prima para a indústria de cosméticos e o segundo agente sinergístico para inseticidas naturais (Estrela et al. 2006).

A pimenta longa é uma espécie predominantemente alógama e com alto grau de heterozigose (Wadt \& Kageyama 2004). Isto influencia, diretamente, no manejo e na domesticação da espécie. Sua propagação se dá tanto por sementes, quanto por estacas. Alcança de $1,60 \mathrm{~m}$ a 1,80 $\mathrm{m}$ de altura, em rápido ciclo vegetativo de um a dois anos (Maia et 
al. 1987). Sua capacidade de rebrota faz do seu cultivo uma atividade perene e ecologicamente correta (Bergo et al. 2005).

Com a proibição da extração predatória do óleo de sassafrás (Ocotea pretiosa Mezz), as indústrias do Sul do Brasil passaram a importar safrol da China e Vietnã, que não conseguem atender à demanda (Bergo et al. 2002, Riva et al. 2011). Assim, a extração do óleo essencial, a partir da pimenta longa, tornou-se uma alternativa comercial promissora. Em razão disto, e para atender à exigente demanda da indústria por teores de safrol acima de $90 \%$ nos óleos essenciais (Bergo et al. 2002), estudos relativos ao cultivo e exploração da pimenta longa têm sido incentivados.

A partir da década de 1990, iniciaram-se expedições de prospecção, no Estado do Acre, com o intuito de coletar o maior número possível de indivíduos de $P$. hispidinervum, visando à obtenção da máxima representatividade da espécie e sua conservação, em Banco Ativo de Germoplasma (BAG) mantido pela Embrapa Acre. Atualmente, o BAG conta com cerca de 2.000 acessos, que estão sendo caracterizados morfológica e fitoquimicamente. A importância do BAG está na conservação ex situ do material genético, além de prover informações sobre os acessos, favorecendo, também, o intercâmbio dos recursos disponíveis (Cruz et al. 2004).

Estudos de divergência genética vegetal são frequentemente realizados com base em descritores botânicos, morfológicos e agronômicos, por apresentarem baixos custos e fácil obtenção (Vargas \& Blanco 2000, Oliveira et al. 2007, Bezerra Neto et al. 2010). Estas análises permitem identificar combinações genéticas que resultem em maior efeito heterótico, de forma a aumentar a possibilidade de obtenção de descendentes com características superiores (Cruz et al. 2004), as quais são reveladas por meio da caracterização morfoagronômica (Sudré et al. 2005).

Em pimenta longa, há evidências de diversidade genética associada a elevados teores de safrol, em populações da região Amazônica (Andrade et al. 2009), com grupos distintos dentro de microrregiões do Alto e Baixo Acre (Wadt \& Kageyama 2004). Entretanto, as informações mais específicas relacionadas às demandas de programas de melhoramento ainda são incipientes.

Nesse contexto, o estudo da divergência genética em pimenta longa, além de incrementar informações sobre a espécie e para a conservação e uso de seus recursos genéticos, traz subsídios para o desenvolvimento de programas de melhoramento da espécie. Ademais, as análises de caracteres morfológicos e fitoquímicos nos acessos podem confirmar o nível de representatividade da espécie, em bancos de germoplasma, bem como dos acessos disponibilizados aos programas de seleção. Caso haja baixa variabilidade, as informações obtidas podem direcionar novas expedições de prospecção e coleta de material genético, buscando aumentar a variabilidade no BAG, e, por conseguinte, as chances de ganhos por seleção, nos programas de melhoramento (Cruz et al. 2004).

Este trabalho objetivou avaliar a divergência genética entre populações de pimenta longa (P. hispidinervum), de ocorrência no Estado do Acre, com base em caracteres morfoagronômicos, buscando-se subsidiar programas de melhoramento genético da espécie, na região.

\section{MATERIAL E MÉTODOS}

Foram avaliadas quinze populações de Piper hispidinervum, mantidas no Banco Ativo de Germoplasma (BAG) da Embrapa Acre, em Rio Branco (AC) (9'58'22”S, 6748'40"W e $160 \mathrm{~m}$ de altitude), entre janeiro de 2009 e fevereiro de 2012. O clima da região é quente e úmido (AWI), conforme a classificação de Köppen, com temperatura máxima anual de $31^{\circ} \mathrm{C}$, mínima de $21^{\circ} \mathrm{C}$, precipitação anual de $1.940 \mathrm{~mm}$ e umidade relativa de $80 \%$. O solo, na área experimental, foi classificado como Argissolo Vermelho-Amarelo distrófico abrúptico, de textura franco-arenosa/argila (Embrapa 2006). A análise de solo, à profundidade de $0,0-0,2 \mathrm{~m}$, resultou em $\mathrm{pH}$ $\left(\mathrm{H}_{2} \mathrm{O}\right)=4,5 ; \mathrm{K}=0,1 \mathrm{cmol}_{\mathrm{c}} \mathrm{kg}^{-1} ; \mathrm{Ca}=1,0 \mathrm{cmol}_{\mathrm{c}} \mathrm{kg}^{-1}$; $\mathrm{Mg}=0,3 \mathrm{cmol}_{\mathrm{c}} \mathrm{kg}^{-1} ; \mathrm{A} 1 \stackrel{\mathrm{c}}{=} 1,4 \mathrm{cmol}_{\mathrm{c}} \mathrm{kg}^{-1} ; \mathrm{M} . \mathrm{O} .=$ $14,0 \mathrm{~g} \mathrm{~kg}^{-1} ; \mathrm{CTC}=1,8 \mathrm{cmol}_{\mathrm{c}} \mathrm{kg}^{-1} ; \mathrm{V}=26 \% ; \mathrm{m}=$ $22 \% ; \mathrm{P}=4,0 \mathrm{mg} \mathrm{kg}^{-1} ;$ areia $=61 \%$; silte $=31 \%$; e argila $=8 \%$.

As populações (todas de polinização aberta) são de diferentes procedências, tendo sido coletadas no Vale do Acre, parte oriental do Estado, no ano de 2000. Cada população foi representada por dez indivíduos, totalizando 150 acessos. A escolha das populações se deu por sua ampla representatividade regional e por revelarem, em estudos prévios, maiores rendimentos de óleo essencial e teor de safrol, em relação às demais populações do BAG (2.000 acessos de 43 populações). 
O experimento foi implantado em delineamento de blocos ao acaso, com quinze tratamentos (populações) e dez repetições (indivíduos ou acessos). O plantio foi conduzido sem irrigação, no espaçamento 2,0 $\mathrm{m} \times 2,0 \mathrm{~m}$, com os tratos culturais recomendados para a cultura (Bergo et al. 2002), e as adubações feitas com base na análise do solo.

Foram analisados oito caracteres morfoagronômicos: comprimento da folha $(\mathrm{mm})$; largura da folha (mm); comprimento do pecíolo (mm); diâmetro do pecíolo $(\mathrm{mm})$; altura da planta $(\mathrm{cm})$; volume de copa $\left(\mathrm{m}^{3}\right)$; rendimento de óleo essencial, em percentagem, relativamente à biomassa verde, em base livre de umidade; e teor de safrol, o componente majoritário neste óleo essencial, expresso como percentagem do óleo essencial. As características morfológicas foram mensuradas com fita métrica, para as variáveis de copa, e paquímetro, para as variáveis foliares. $\mathrm{O}$ volume de copa foi estimado com base na fórmula proposta por Ledo et al. (1999): $V=2 / 3 \pi R^{2} H$, em que $\mathrm{V}$ é o volume, $\mathrm{R}$ o raio médio da copa e $\mathrm{H}$ a altura da planta.

As características fitoquímicas foram analisadas no Laboratório de Óleos Essenciais da Embrapa Acre. A biomassa verde da parte aérea utilizada nestas análises foi levada, imediatamente após a colheita, ao Laboratório, com umidade em torno de $70 \%$. O teor de umidade da biomassa foi determinado para realizar os cálculos de rendimento em base livre de umidade, conforme descrito por Figueiredo et al. (2004). Foram utilizados 6,0 $\mathrm{g}$ de biomassa verde, picotada e misturada em balão de fundo redondo $(250 \mathrm{~mL})$ com $30 \mathrm{~mL}$ de tolueno. Os balões com as amostras ficaram expostos em manta aquecedora, à temperatura de $120^{\circ} \mathrm{C}$. Sobre os balões, foram montados o separador de água graduado Dean-Strak e o condensador de refluxo. Pelo topo do condensador, foram colocados mais $80 \mathrm{~mL}$ de tolueno, para permitir o retorno do solvente ao balão. $\mathrm{O}$ processo de extração foi conduzido por 180 minutos e, ao final, realizou-se a leitura da quantidade de água extraída da biomassa.

O óleo essencial foi extraído pelo método de coobação ou recirculação de água condensada (Heath 1977), para posterior quantificação do composto majoritário (safrol), por meio de cromatografia gasosa. A extração foi realizada com amostras de $90 \mathrm{~g}$ de biomassa (verde e picotada), para cada acesso, misturadas a $450 \mathrm{~mL}$ de água destilada e submetidas a $100^{\circ} \mathrm{C}$, em manta aquecedora em aparato Clevenger, por 180 minutos. Então, foi coletada a fração mais densa constituída de óleo.

O cromatógrafo a gás (HP, modelo 6890) é equipado com detector de ionização de chama e coluna capilar de $30 \mathrm{~m}$ de comprimento e $25 \mathrm{~mm}$ de diâmetro interno, e utiliza hélio, como gás de arraste. $\mathrm{O}$ injetor interno e o detector foram mantidos à temperatura de $250^{\circ} \mathrm{C}$, com injeção em volume reduzido ("split" de, aproximadamente, 1:100). A temperatura inicial do forno foi mantida em $80^{\circ} \mathrm{C}$, por dez minutos, com incremento de $4^{\circ} \mathrm{C}$ por minuto, até atingir $140^{\circ} \mathrm{C}$, com posterior incremento de $20^{\circ} \mathrm{C}$ por minuto, até $260^{\circ} \mathrm{C}$, que era a temperatura máxima programada (Figueiredo et al. 2004).

O cálculo do rendimento de óleo essencial foi realizado conforme proposto por Santos et al. (2004), considerando-se $100 \%$ de eficiência de extração, em escala de laboratório:

$$
R E N D=\frac{v o}{b m-(b m \cdot u / 100)} \cdot 100
$$

em que $R E N D$ é expresso em \% ( $\mathrm{mL}$ de óleo essencial em $100 \mathrm{~g}$ de biomassa seca), vo é o volume de óleo obtido diretamente na escala do coletor, $\mathrm{bm}$ a biomassa vegetal $(\mathrm{g})$ e $(\mathrm{bm} . u / 100)$ a quantidade de umidade ou água presente na biomassa.

Realizou-se análise de variância univariada e, em seguida, os valores médios das variáveis, estimados para cada população, foram ordenados segundo o teste de agrupamento Scott-Knott, a 5\% (Scott \& Knott 1974). Para o estudo da divergência genética entre as populações, empregaram-se análises multivariadas, incluindo agrupamento pelos métodos de otimização de Tocher e do vizinho mais próximo, ambos com base na distância generalizada de Mahalanobis, e, ainda, a análise de variáveis canônicas (Cruz et al. 2004).

O estabelecimento dos grupos de similaridade, no agrupamento por vizinho mais próximo, foi feito de forma subjetiva, buscando-se detectar alguma estruturação espacial entre os grupos (formação de grupos com distribuição geográfica próxima). Pela análise de variáveis canônicas, gerou-se um gráfico de dispersão tridimensional, que possibilitou verificar a consistência destes agrupamentos. Esta técnica se baseia nas informações entre e dentro das populações, para formar um conjunto de dados simplificados e independentes entre si (Cruz et al. 2004). A contribuição relativa percentual dos caracteres na diversidade 
genética foi quantificada segundo o método de Singh (1981), com identificação de variáveis passíveis de descarte e posterior análise do conjunto remanescente. Este processo foi repetido até nenhuma distorção na análise de agrupamento, pelo método de Tocher, ser observada. Os dados foram padronizados e as análises realizadas no programa computacional Genes (Cruz 2006).

\section{RESULTADOS E DISCUSSÃO}

A análise de variância e o agrupamento das médias das populações por Scott-Knott (Tabela 1) mostraram que todas as características expressaram diferenças significativas entre as populações. Esta variabilidade também já foi observada em outros estudos, na região Amazônica, principalmente para características fitoquímicas, o que pode estar condicionado a fatores fisiográficos e, sobretudo, genéticos (Braga et al. 2005, Andrade et al. 2009, Riva et al. 2011). Portanto, os resultados indicam que os acessos são agronomicamente diferentes, nos caracteres estudados, com possibilidades de ganhos por seleção. Isto ocorre porque a seleção e o intercruzamento de populações geneticamente variáveis aumentam a frequência de alelos favoráveis nas populações base, melhorando a expressão fenotípica dos caracteres de interesse (Rosado et al. 2009, Krause et al. 2012).

No agrupamento de médias (Tabela 1), os caracteres volume de copa, rendimento de óleo essencial e teor de safrol apresentaram a formação de três grupos, cada um, com maior variabilidade nos dois primeiros, e coeficientes de variação (CV\%) considerados alto e médio, respectivamente (Ferreira 1991). O restante das características mostrou apenas dois grupos. A análise de agrupamento das médias possibilitou a visualização da variabilidade entre as populações analisadas, resultado, também, previamente indicado pelo teste F. Segundo Bezerra Neto et al. (2010), a variabilidade é importante no aproveitamento da heterose e na obtenção de segregantes com características de interesse em programas de melhoramento genético.

Os valores médios de rendimento de óleo essencial e teor de safrol (Tabela 1) foram maiores que os reportados por Braga et al. (2005), os quais obtiveram rendimentos em biomassa verde de $0,2 \%$ a $1,3 \%$ e teor de safrol de $57 \%$, porém, menores que os observados por Andrade et al. (2009) e Riva et al. (2011), cujos rendimentos em biomassa seca foram de $4,8 \%$ a $5,42 \%$ e os teores de safrol alcançaram $97 \%$. Deve-se ressaltar que valores de rendimento de óleo

Tabela 1. Estimativas de médias aritméticas de populações de Piper hispidinervum para oito caracteres morfoagronômicos ${ }^{1}$, avaliados entre 2009 e 2012 (Rio Branco, AC, 2012).

\begin{tabular}{|c|c|c|c|c|c|c|c|c|}
\hline \multirow{2}{*}{ População } & $\mathrm{CFO}$ & LFO & CPE & DPE & \multirow{2}{*}{$\begin{array}{c}\text { ALT } \\
\mathrm{cm} \\
\end{array}$} & \multirow{2}{*}{$\frac{\mathrm{VCOP}}{\mathrm{m}^{3}}$} & REND & SAFROL \\
\hline & & -1 & & & & & \multicolumn{2}{|c|}{$\%$} \\
\hline 1 & $131,80 \mathrm{~b}$ & $44,69 \mathrm{~b}$ & $2,51 \mathrm{~b}$ & $1,72 \mathrm{~b}$ & $261,80 \mathrm{a}$ & $8,31 \mathrm{~b}$ & $3,67 \mathrm{~b}$ & $87,5 \mathrm{a}$ \\
\hline 2 & $128,34 \mathrm{~b}$ & $43,59 \mathrm{~b}$ & $2,87 \mathrm{~b}$ & $1,76 \mathrm{~b}$ & $239,70 \mathrm{~b}$ & $5,25 \mathrm{c}$ & $4,20 \mathrm{~b}$ & $80,7 \mathrm{~b}$ \\
\hline 3 & $143,12 \mathrm{a}$ & $48,07 \mathrm{a}$ & $2,58 \mathrm{~b}$ & $1,70 \mathrm{~b}$ & $244,80 \mathrm{~b}$ & $7,02 \mathrm{c}$ & $3,97 \mathrm{~b}$ & $93,9 \mathrm{a}$ \\
\hline 4 & $143,98 \mathrm{a}$ & $45,24 \mathrm{~b}$ & $3,01 \mathrm{a}$ & $1,74 \mathrm{~b}$ & $217,30 \mathrm{~b}$ & $4,74 \mathrm{c}$ & $2,76 \mathrm{c}$ & $70,7 \mathrm{c}$ \\
\hline 5 & $137,52 \mathrm{~b}$ & $47,39 \mathrm{a}$ & $2,72 \mathrm{~b}$ & $1,54 \mathrm{~b}$ & $237,80 \mathrm{~b}$ & $6,70 \mathrm{c}$ & $4,34 \mathrm{~b}$ & $84,4 \mathrm{~b}$ \\
\hline 6 & $151,83 \mathrm{a}$ & $49,01 \mathrm{a}$ & $2,58 \mathrm{~b}$ & $1,80 \mathrm{~b}$ & $219,20 \mathrm{~b}$ & $5,25 \mathrm{c}$ & $2,88 \mathrm{c}$ & $66,5 \mathrm{c}$ \\
\hline 7 & $142,00 \mathrm{a}$ & $49,04 \mathrm{a}$ & $3,05 \mathrm{a}$ & $1,77 \mathrm{~b}$ & $228,60 \mathrm{~b}$ & $5,44 \mathrm{c}$ & $3,04 \mathrm{c}$ & $82,2 \mathrm{~b}$ \\
\hline 8 & $143,85 \mathrm{a}$ & $42,97 \mathrm{~b}$ & 3,09 a & $1,83 \mathrm{a}$ & $235,00 \mathrm{~b}$ & $6,37 \mathrm{c}$ & $4,11 \mathrm{~b}$ & $64,3 \mathrm{c}$ \\
\hline 9 & $133,04 \mathrm{~b}$ & $43,19 \mathrm{~b}$ & $2,68 \mathrm{~b}$ & $1,75 \mathrm{~b}$ & $228,50 \mathrm{~b}$ & $5,63 \mathrm{c}$ & $2,72 \mathrm{c}$ & $83,1 \mathrm{~b}$ \\
\hline 10 & $152,57 \mathrm{a}$ & $51,08 \mathrm{a}$ & $3,01 \mathrm{a}$ & $1,94 \mathrm{a}$ & $251,10 \mathrm{a}$ & $7,57 \mathrm{~b}$ & $5,06 \mathrm{a}$ & $89,1 \mathrm{a}$ \\
\hline 11 & $145,88 \mathrm{a}$ & $49,41 \mathrm{a}$ & $2,93 \mathrm{a}$ & $1,85 \mathrm{a}$ & $245,50 \mathrm{~b}$ & $6,69 \mathrm{c}$ & $2,88 \mathrm{c}$ & $78,9 \mathrm{~b}$ \\
\hline 12 & $137,13 \mathrm{~b}$ & $52,73 \mathrm{a}$ & $3,14 \mathrm{a}$ & $1,84 \mathrm{a}$ & $245,40 \mathrm{~b}$ & $5,72 \mathrm{c}$ & $3,80 \mathrm{~b}$ & $81,3 \mathrm{~b}$ \\
\hline 13 & $143,41 \mathrm{a}$ & $47,90 \mathrm{a}$ & $3,34 \mathrm{a}$ & $1,75 \mathrm{~b}$ & $232,10 \mathrm{~b}$ & $5,79 \mathrm{c}$ & $4,88 \mathrm{a}$ & $85,1 \mathrm{~b}$ \\
\hline 14 & $145,99 \mathrm{a}$ & $50,30 \mathrm{a}$ & $2,97 \mathrm{a}$ & $1,95 \mathrm{a}$ & $268,80 \mathrm{a}$ & $10,40 \mathrm{a}$ & $3,99 \mathrm{~b}$ & $85,2 \mathrm{~b}$ \\
\hline 15 & $159,96 \mathrm{a}$ & $55,80 \mathrm{a}$ & $3,73 \mathrm{a}$ & $1,98 \mathrm{a}$ & $270,00 \mathrm{a}$ & $6,22 \mathrm{c}$ & $2,43 \mathrm{c}$ & $81,5 \mathrm{~b}$ \\
\hline Média & 140,81 & 47,40 & 2,91 & 1,77 & 238,17 & 6,359 & 3,60 & 79,91 \\
\hline QM Trat. $^{2}$ & $835,11 *$ & $168,45^{*}$ & $0,126^{*}$ & $0,12^{*}$ & $3.525,56^{*}$ & $21,28^{*}$ & $6,28 *$ & $612,45^{*}$ \\
\hline $\mathrm{CV}(\%)$ & 16,52 & 18,10 & 25,15 & 17,86 & 16,34 & 39,04 & 28,80 & 15,00 \\
\hline
\end{tabular}

Médias seguidas pela mesma letra minúscula, nas colunas, pertencem ao mesmo grupo, pelo teste Scott-Knott, a $5 \%$. ${ }^{1} \mathrm{CFO}$ : comprimento da folha; LFO: largura da folha; CPE: comprimento do pecíolo; DPE: diâmetro do pecíolo; ALT: altura da planta; VCOP: volume de copa; REND: rendimento de óleo essencial em base livre de umidade; SAFROL: teor de safrol. ${ }^{2}$ QM Trat.: quadrado médio de tratamentos, na análise de variância do caráter. * Valores significativos a 5\%, pelo teste F. 
essencial e teor de safrol em biomassa seca, em geral, são maiores, devido ao fato de a secagem concentrar o componente majoritário (Smith \& Kassim 1979). Este processo, no entanto, pode ocasionar perda de compostos de interesse, pela difusão de óleo essencial carregado pela umidade, acarretando, também, a perda de outros compostos e alteração na qualidade do óleo (Braga et al. 2005). De qualquer modo, os resultados de algumas populações com rendimentos de óleo acima de $4 \%$ e teores de $85 \%$ ou mais de safrol são tidos como satisfatórios (Bergo et al. 2005, Riva et al. 2011).

Os grupos de maior volume de copa, com médias significativamente superiores, mostraram valores acima de $7,5 \mathrm{~m}^{3}$ de biomassa por indivíduo e alturas de 251-268 $\mathrm{cm}$. A estimativa de volume de copa é importante na caracterização e seleção de materiais genéticos, uma vez que tal característica, juntamente com o rendimento do óleo essencial e teor do composto majoritário, condiciona o volume de produção do óleo essencial (Bergo et al. 2005, Wadt \& Pacheco 2006). Chaves et al. (2011), da mesma forma, observaram que a produção de biomassa de Piper callosum foi diretamente proporcional à produção de óleo essencial, porém, ambos inversamente proporcionais ao aumento do arranjo espacial da cultura. Neste sentido, Miranda (2002) verificou que a produção de óleo essencial, em populações nativas de $P$. hispidinervum, representou apenas $15 \%$ da produtividade obtida em plantios comerciais, devido à baixa produção de biomassa. Assim, sugeriu o adensamento de indivíduos no campo, de forma a aumentar o volume de copa.

$\mathrm{O}$ grupo com os maiores valores de largura e comprimento de folha variou $142,0-160,0 \mathrm{~mm}$ e $47,4-55,8 \mathrm{~mm}$, respectivamente, e de comprimento e diâmetro de pecíolo 3,01-3,73 mm e 1,83-1,98 mm, respectivamente, com CV\% entre médio e alto (Ferreira 1991). Isto evidencia variabilidade, também, nestas características. Os valores de largura e comprimento de folhas estão diretamente associados ao teor de safrol, uma vez que o óleo essencial obtido da biomassa de pimenta longa, sem participação de folhas, tem menor valor comercial (Figueiredo et al. 2004). Desta forma, maiores valores de comprimento e largura de folhas são agronomicamente interessantes, por proporcionarem melhor qualidade do óleo essencial.

A aplicação do método de otimização de Tocher permitiu identificar três grupos de dissimi- laridade (Tabela 2). O grupo I, composto por seis populações, é caracterizado pelos menores valores de rendimento do óleo essencial. Já o grupo II caracterizou-se por apresentar os maiores teores de safrol. O grupo III foi formado apenas pela população 8 , cuja característica principal, que a diferencia das demais, é o baixo teor de safrol (Tabela 1). Este mesmo tipo de agrupamento foi observado no dendrograma obtido pelo método do vizinho mais próximo, com pequenas variações na posição das populações, dentro dos grupos (Figura 1).

No agrupamento das populações, o corte do dendrograma em 53\% de dissimilaridade sugere uma possível estruturação espacial da variabilidade genética da espécie, agrupando, principalmente, as populações oriundas da região de Plácido de Castro e Acrelândia (populações $2 ; 12 ; 10 ; 13 ; 3 ; 5 ; 1 ;$ e 14) e isolando a população de Brasileia (população 8), com menor teor de safrol (Tabela 1).

O valor máximo das distâncias generalizadas de Mahalanobis foi de 22,29, que ocorreu entre as

Tabela 2. Agrupamento de quinze populações de pimenta longa, pelo método de Tocher, aplicado a distâncias generalizadas de Mahalanobis, com base em oito caracteres morfoagronômicos (Rio Branco, AC, 2012).

\begin{tabular}{crrrrrrrrr}
\hline Grupo & \multicolumn{10}{c}{ População } \\
\hline I & & 7 & 11 & 9 & 4 & 6 & 15 & \\
II & 10 & 13 & 5 & 3 & 1 & 2 & 12 & 14 \\
III & & & & 8 & & & & & \\
\hline
\end{tabular}

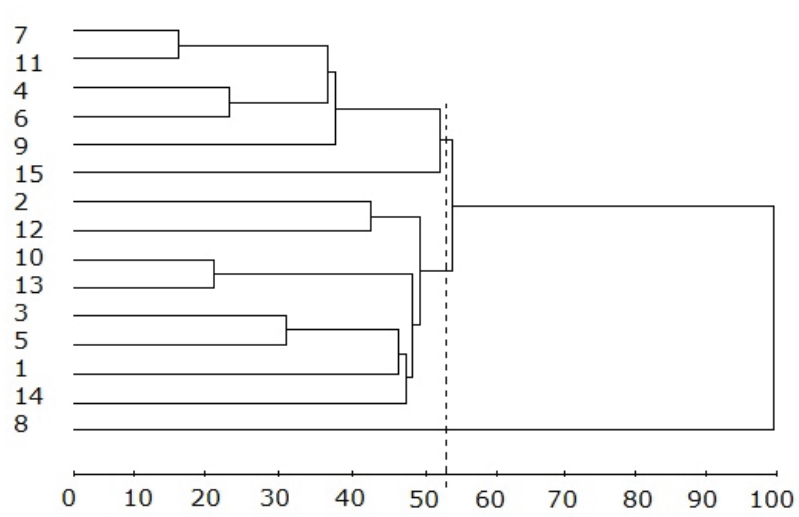

Figura 1. Dendrograma de dissimilaridades genéticas entre quinze populações de pimenta longa, obtido pelo método do vizinho mais próximo, com base nas distâncias generalizadas de Mahalanobis, para oito caracteres morfoagronômicos (corte, na distância, igual a 53\%) (Rio Branco, AC, 2012). 
populações 3 e 8 , nos grupos II e III, e o mínimo foi de 0,89 , entre as populações 7 e 11 , dentro do grupo I. A distância média do grupo III, formado apenas pela população 8, em relação às demais populações, foi de 11,98, revelando-se, assim, o grupo mais divergente. Considerando-se as distâncias dentro dos grupos, o grupo II foi o mais heterogêneo, com distância média de 4,77, entre as suas populações, enquanto o grupo I apresentou distância média de 3,82, revelando-se o mais homogêneo.

A estruturação dos grupos indica uma tendência de agrupamento segundo a distribuição geográfica das populações, no Estado do Acre. A população 8 (grupo III), por exemplo, com o menor teor médio de safrol (Tabela 1), é oriunda da região de Brasileia (ao sul do Estado), de onde provêm, ainda, as populações 6 e 4, também com baixos teores deste componente, além da população 7, com baixo rendimento de óleo essencial. Já o grupo II, com exceção da população 10, proveniente da região de Assis Brasil, ao sul, reuniu as populações com os maiores valores de rendimento de óleo essencial e teor de safrol, as quais são oriundas da região de Plácido de Castro e Acrelândia, no extremo leste do Estado. Wadt \& Kageyama (2004) observaram distribuição semelhante das populações de $P$. hispidinervum, no Vale do Acre, sugerindo estruturação espacial da variabilidade genética da espécie.

$\mathrm{Na}$ análise de variáveis canônicas, observou-se que as três primeiras variáveis canônicas (VC) explicaram $76,12 \%$ da variância total acumulada. O primeiro fator foi responsável por $41,07 \%$, o segundo por $22,34 \%$ e o terceiro por $12,71 \%$ da variabilidade dos dados originais. Assim, as três primeiras variáveis (VC) foram utilizadas para a formação do gráfico de dispersão (Figura 2).

Pela análise de dispersão gráfica em variáveis canônicas, foi possível identificar quatro grupos de similaridade (Figura 2), resultado muito próximo daquele obtido por meio do agrupamento pelo método de Tocher (Tabela 2). A formação de grupos coincidentes, com a utilização de métodos complementares para caracteres morfoagronômicos, também é relatada em palmáceas (Vargas \& Blanco 2000, Oliveira et al. 2007), tomateiro (Karasawa et al. 2005), pimenta e pimentão (Sudré et al. 2005), o que indica consistência dos resultados de similaridade, na composição dos grupos.

O grupo 1 ficou constituído pelas populações $4 ; 6 ; 7 ; 9 ; 11 ;$ e 15 , sendo caracterizado pelos menores

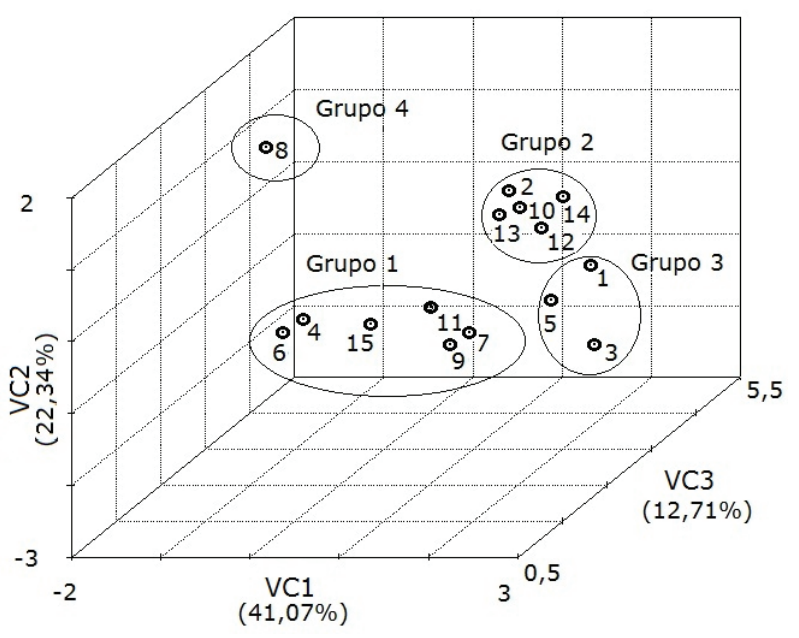

Figura 2. Dispersão gráfica dos escores dos caracteres morfoagronômicos, em relação aos três eixos principais de variáveis canônicas (VC1, VC2 e VC3), avaliados em quinze populações de pimenta longa (Rio Branco, AC, 2012).

valores de rendimento de óleo essencial e teor de safrol, associados aos maiores valores de comprimento e largura de folhas. O grupo 2, composto pelas populações 2; 12; 13; e 14, da região de Plácido de Castro e Acrelândia, mais a população 10, de Assis Brasil, caracterizou-se pelos maiores valores de rendimento de óleo essencial e teores de safrol, além de menor volume de copa. O grupo 3, com as populações 1; 3; e 5, oriundas de Plácido de Castro e Acrelândia, apresentou valores inferiores para as características morfológicas e teores elevados de safrol, associados ao alto rendimento de óleo essencial. Já o grupo 4, constituído apenas pela população 8 , da região de Brasileia, caracterizou-se pelo baixo teor de safrol e menor comprimento e largura de folha (Tabela 1).

Considerando-se a possibilidade de predição de heterose por análise multivariada e da escolha de genitores (populações) divergentes, para se elevar a probabilidade de ganho por seleção, em programas de melhoramento (Sudré et al. 2005, Oliveira et al. 2007), os resultados obtidos permitem fazer indicações de alguns cruzamentos. A principal delas seria entre acessos das populações dos grupos 2 e 3 (Figura 2). Um exemplo disto seria o cruzamento entre a população 3 e acessos das populações 10 ou 13, uma vez que a primeira tem elevado teor de safrol, embora com rendimento apenas mediano de óleo essencial, enquanto as outras duas apresentam elevado rendimento deste óleo. Outra indicação seria o cruzamento entre a população 14 , com elevado 
volume de copa, e a população 1, com elevado teor de safrol.

As populações que compõem os grupos 2 e 3 , obtidos por análise de variáveis canônicas que são as mesmas do grupo II, formado no agrupamento de Tocher, apresentam potencial para inclusão em programas de melhoramento genético da espécie. No entanto, em etapas seguintes do processo de avaliação, recomenda-se maior número de populações, com a finalidade de apoiar os resultados nos caracteres de maior discriminação, bem como aumentar a variabilidade e o potencial agronômico e industrial da espécie.

A importância relativa dos caracteres no agrupamento das populações, segundo o método de Singh (1981), destacou o caráter teor de safrol, com contribuição de $26,85 \%$, seguido do rendimento de óleo essencial, com 19,19\%, e do volume de copa, com 14,82\% (Tabela 3). Assim, estes são considerados caracteres relevantes para a discriminação dos acessos avaliados neste germoplasma.

As características foram descartadas, da menor para a maior contribuição relativa, até que o agrupamento original fosse alterado. A retirada do caráter de menor contribuição relativa (altura da planta - ALT) não alterou a composição dos grupos. Segundo Oliveira et al. (2004), isto indica que tal característica não é relevante para a divergência, provavelmente em função do aspecto redundância (Cruz et al. 2004), uma vez que está diretamente relacionada ao volume de copa.

Até o descarte da variável comprimento do pecíolo (CPE), com a retirada anterior de diâmetro do pecíolo (DPE), apenas a ordem das populações

Tabela 3. Contribuição relativa dos caracteres para a análise de diversidade, segundo critério de Singh (1981), por meio da distância generalizada de Mahalanobis (Rio Branco, AC, 2012).

\begin{tabular}{lc}
\hline Variável $^{1}$ & Contribuição (\%) \\
\hline SAFROL & 26,86 \\
REND & 19,19 \\
VCOP & 14,82 \\
LFO & 10,70 \\
CFO & 9,76 \\
CPE & 7,30 \\
DPE & 7,04 \\
ALT & 4,33 \\
\hline
\end{tabular}

${ }^{1}$ SAFROL: teor de safrol (\%); REND: rendimento em base livre de umidade (\%); VCOP: volume de copa $\left(\mathrm{m}^{3}\right)$; LFO: largura da folha $(\mathrm{mm})$; CFO: comprimento da folha (mm); CPE: comprimento do pecíolo (mm); DPE: diâmetro do pecíolo $(\mathrm{mm})$; ALT: altura da planta $(\mathrm{m})$. dentro dos grupos foi alterada. Isto sugere, segundo Abreu et al. (2004), que as variáveis, no caso ALT, DPE e CPE, não influenciam, de modo relevante, a variabilidade dos acessos, podendo, sua utilização, ser revista em estudos posteriores, o que otimizaria o tempo de trabalho e recursos (Cruz et al. 2004).

A eliminação do comprimento da folha (CFO) alterou o agrupamento das populações, aumentando o número de grupos, o que indica sua forte influência e dos demais caracteres (SAFROL, REND e VCOP), na discriminação das populações avaliadas (Oliveira et al. 2004).

\section{CONCLUSÕES}

1. As populações de pimenta longa (Piper hispidinervum C. DC.) avaliadas possuem variabilidade genética para os caracteres agronômicos analisados, sendo discriminadas, principalmente, pelo teor de safrol, rendimento de óleo essencial e volume de copa.

2. A variabilidade genética, nessas populações, apresentou tendência de estruturação espacial, com estratificação em dois a quatro grupos principais, sendo que as populações provenientes da região de Plácido de Castro e Acrelândia apresentaram maior potencial agronômico para compor programas regionais de melhoramento genético da espécie.

\section{AGRADECIMENTOS}

Ao Tesouro Nacional e ao Conselho Nacional de Desenvolvimento Científico e Tecnológico (CNPq), pelo auxílio financeiro à pesquisa.

\section{REFERÊNCIAS}

ABREU, F. B. et al. Divergência genética entre acessos de feijão de vagem de hábito de crescimento indeterminado. Horticultura Brasileira, Brasília, DF, v. 22, n. 3, p. 547552, 2004.

ANDRADE, E. H. de A.; GUIMARÃES, E. F.; MAIA, J. G. S. Variabilidade química em óleos essenciais de espécies de Piper da Amazônia. Belém: FEQ/UFPA, 2009.

BERGO, C. L.; MENDONÇA, H. A.; SILVA, M. R. da. Efeito da época e frequência de corte de pimenta longa (Piper hispidinervum C. DC.) no rendimento de óleo essencial. Acta Amazonica, Manaus, v. 35, n. 2, p. 111117, 2005. 
BERGO, C. L. et al. Cultivo da pimenta longa (Piper hispidinervum) na Amazônia Ocidental. Rio Branco: Embrapa Acre, 2002. (Sistemas de produção, 1).

BEZERRA NETO, F. V. et al. Descritores quantitativos na estimativa da divergência genética entre genótipos de mamoneira utilizando análises multivariadas. Revista Ciência Agronômica, Fortaleza, v. 41, n. 2, p. 294-299, 2010.

BRAGA, N. P.; CREMASCO, M. A.; VALLE, R. C. C. R. The effects of fixed-bed drying on the yield and composition of essential oil from long pepper (Piper hispidinervum C. DC.) leaves. Brazilian Journal of Chemical Engineering, São Paulo, v. 22, n. 2, p. 257-262, 2005.

CHAVES, F. C. M. et al. Biomass production and chemical composition of essential oil of Piper callosum as affected by spacing in Manaus, Amazonas State, Brazil. Acta Horticulturae, Lisboa, n. 925, p. 233-236, 2011.

CRUZ, C. D. Programa Genes: estatística experimental e matrizes. Viçosa: UFV, 2006.

CRUZ, C. D.; REGAZZI, A. J.; CARNEIRO, P. C. S. Modelos biométricos aplicados ao melhoramento genético. Viçosa: UFV, 2004.

EMPRESA BRASILEIRA DE PESQUISA AGROPECUÁRIA (Embrapa). Centro Nacional de Pesquisa de Solos. Sistema brasileiro de classificação de solos. 2. ed. Rio de Janeiro: Embrapa Solos, 2006.

ESTRELA, L. L. V. et al. Toxicidade de óleos essenciais de Piper aduncum e Piper hispidinervum em Sitophilus zeamais. Pesquisa Agropecuária Brasileira, Brasília, DF, v. 41, n. 2, p. 217-222, 2006.

FERREIRA, P. V. Estatística experimental aplicada à agronomia. Maceió: Edufal, 1991.

FIGUEIREDO, F. J. C. et al. Rendimento e qualidade físico-química de óleo essencial extraído de diferentes composições da biomassa aérea de pimenta longa. Belém: Embrapa Amazônia Oriental, 2004. (Boletim de pesquisa e desenvolvimento, 33).

GOTTLIEB, O. R. et al. Óleos essenciais da Amazônia VII. Acta Amazonica, Manaus, v. 11, n. 1, p. 143-148, 1981.

HEATH, H. B. Flavorings, condiments and relishes. In: DESROSIER, N. W. (Ed.). Elements of food technology. Wesrport: The Avipublishing Company, 1977. p. 666-701.

KARASAWA, M. et al. Aplicação de métodos de agrupamento na quantificação da divergência genética entre acessos de tomateiro. Horticultura Brasileira, Vitória da Conquista, v. 23, n. 4, p. 1000-10005, 2005.
KRAUSE, W. et al. Ganho de seleção no melhoramento genético intrapopulacional do maracujazeiro-amarelo. Pesquisa Agropecuária Brasileira, Brasília, DF, v. 47, n. 1, p. 51-57, 2012.

LEDO, A. da S. et al. Porta-enxertos para laranjeirasdoce (Citrus sinensis (L.) OSB.), em Rio Branco, Acre. Pesquisa Agropecuária Brasileira, Brasília, DF, v. 34, n. 7, p. 1211-1216, 1999.

MAIA, J. G. S. et al. Espécies de Piper da Amazônia ricas em safrol. Química Nova, São Paulo, v. 10, n. 3, p. 200-204, 1987.

MIRANDA, E. M. de. Caracterização e avaliação produtiva de uma população nativa de pimenta longa (Piper hispidinervum C. DC.) no seringal Cachoeira, AC, Brasil. Acta Amazonica, Manaus, v. 32, n. 1, p. 9-20, 2002.

OLIVEIRA, A. C. B. et al. Divergência genética e descarte de variáveis em alface cultivada sob sistema hidropônico. Acta Scientiarum, Maringá, v. 26, n. 2, p. 211-217, 2004.

OLIVEIRA, M. do S. P. de; FERREIRA, D. F.; SANTOS, J. B. dos. Divergência genética entre acessos de açaizeiro fundamentada em descritores morfoagronômicos. Pesquisa Agropecuária Brasileira, Brasília, DF, v. 42, n. 4, p. 501-506, 2007.

RIVA, D. et al. Estudo da adaptação da espécie Piper hispidinervum C. DC. (pimenta longa) à região do Vale do Itajaí - SC, através da composição química do óleo essencial obtido por hidrodestilação por micro-ondas e convencional. Acta Amazonica, Manaus, v. 41, n. 2, p. 297-302, 2011.

ROSADO, A. M. et al. Ganhos genéticos preditos por diferentes métodos de seleção em progênies de Eucalyptus urophylla. Pesquisa Agropecuária Brasileira, Brasília, DF, v. 44, n. 12, p. 1653-1659, 2009.

SANTOS, A. S. et al. Descrição de sistema e de métodos de extração de óleos essenciais e determinação de umidade de biomassa em laboratório. Belém: Embrapa Amazônia Oriental, 2004. (Comunicado técnico, 99).

SCOTT, A. J.; KNOTT, M. A. Cluster analysis methods for grouping means in the analysis of variance. Biometrics, Raleigh, v. 30, n. 3, p. 507-512, 1974.

SINGH, D. The relative importance of characters affecting genetic divergence. The Indian Journal of Genetic and Plant Breeding, New Delhi, v. 41, n. 1, p. 237-245, 1981.

SMITH, R. M.; KASSIM, H. The essential oil of Piper aduncum from Fiji. New Zealand Journal of Science, Wellirgton, v. 22, n. 1, p. 127-128, 1979. 
SUDRÉ, C. P. et al. Divergência genética entre acessos de pimenta e pimentão utilizando técnicas multivariadas. Horticultura Brasileira, Vitória da Conquista, v. 23, n. 1, p. 22-27, 2005.

VARGAS, A.; BLANCO, F. A. Fruit characterization of Cocos nucifera L. (Arecaceae) cultivars from the Pacific Coast of Costa Rica and the Philippines. Genetic Resources and Crop Evolution, New York, v. 47, n. 5, p. 483-487, 2000.
WADT, L. H. de O.; KAGEYAMA, P. Y. Estrutura genética e sistema de acasalamento de Piper hispidinervum. Pesquisa Agropecuária Brasileira, Brasília, DF, v. 39, n. 2, p. 151-157, 2004.

WADT, P. G. S.; PACHECO, E. P. Efeito da adubação nitrogenada, em diferentes densidades de plantio, na produção de biomassa de pimenta longa (Piper hispidinervum C. DC.). Revista de Biologia e Ciências da Terra, Campina Grande, v. 6, n. 2, p. 334-340, 2006. 